\title{
Research on the Influence of Sowing Age and Density in Winter Barley Production, with Organic and Mineral Fertilization
}

\author{
Daniela TRIFAN ${ }^{1^{*}}$, Marcel BULARDA ${ }^{1}$ \\ ${ }^{1}$ Agricultural Research and Development Station of Braila, Romania, Sos. Vizirului, Km. 9, Braila, \\ Romania, cod. 810008 \\ *Corresponding author: dana.trifan@yahoo.com
}

Bulletin USAMV series Agriculture 72(2)/2015

Print ISSN 1843-5246; Electronic ISSN 1843-5386

DOI 10.15835/buasvmcn-agr: 11338

\begin{abstract}
The polifactorial experience was held in the agricultural year 2013 - 2014, in the Experimental Center Chiscani. Experience had two sub-experience, each with two experimental factors, as follows: I: sowing time (factor B) and different fertilization (factor C); and II: different sowing densities (factor A) and different fertilization (factor C). At harvesting were made biometric measurements, and determining production (kg/ha), thousand grain weight $(\mathrm{g})$ and hectolitre mass $(\mathrm{kg} / \mathrm{hl})$ for each experimental variant. The results were statistically analysed by a method of analysis of variance (ANOVA) and correlation. The average number of ears/plant, average number of kernels/spike, kernels per ear mass was positively impacted by organic fertilization, which significantly influenced the increase in production compared to chemically fertilized variants. In the present research work we demonstrated that winter barley production can be improved by application of organic fertilizer, especially in lower sowing densities and for correction of delayed sowing. The best production results were obtained from version B3 fertilized biological, meaning an increase of production of $1300 \mathrm{~kg} / \mathrm{ha}$, that is $20 \%$ from the average experience.
\end{abstract}

Keywords: barley, densities, fertilizers, sowing time.

\section{INTRODUCTION}

Improving performance depends on understanding how the crop develops and grows in the field. Such knowledge is vital to improve on-farm management and supporting research (Collen, 2006). In general, the results from many trials suggest that the best time for sowing winter barley is between the last 10 days of September and the first 20 days of October, providing that soil and weather conditions are suitable. (Donald, 2015).

The importance of sowing density and sowing time is indisputable for getting higher barley production, especially given the current climate changes. On the other hand, fertilization is a very important method to increase production, as so organic methods of fertilization is important for protecting the environment and maintaining soil fertility.

Barley can scavenge significant amounts of nitrogen and improves $\mathrm{P}$ and $\mathrm{K}$ cycling if the residue is not removed (Jensen, 1996 and Izzauralde, 1990).

\section{MATERIALS AND METHODS}

The polifactorial experience was held in the agricultural year 2013 - 2014, in the Experimental Center Chiscani, of SCDA Braila. Experience had two sub-experiences, each with two experimental factors, as follows: 
- Sub-experience I: sowing time (factor B) and different fertilization (factor $\mathrm{C}$ ) (figure $1 \mathrm{a}$ );

- Sub-experience II: different sowing densities (factor A) and different fertilization (factor C) (figure $1 \mathrm{~b}$ ).

The experimental factors had the following graduations:

$\mathrm{A}=$ sowing densities with 6 graduations $(\mathrm{A} 1=$ $250 ; \mathrm{A} 2=350 ; \mathrm{A} 3=450 ; \mathrm{A} 4=550 ; \mathrm{A} 5=650 ; \mathrm{A} 6$ $=750$ g.s. $/$ sqm) (figure $1-$ green);

$\mathrm{B}=$ sowing time with 5 graduations (B1 - 1 Oct. 2013; B2 - 10. Oct. 2013; B3 - 21. Oct. 2013; B4 - 30.0ct. 2013; B5 - 6.Nov. 2013);

$\mathrm{C}=$ fertilization methods - with 2 graduation $(\mathrm{C} 1$ chemical fertilization - complex fertilizer N-P-K $=18-46-0-204 \mathrm{~kg} / \mathrm{ha}$, in 26 Sept. 2013 and urea $175 \mathrm{~kg} / \mathrm{ha}$, in 31 Mar. 2014; C2 - biological fertilization: Algafix 2l/ha, in 6 May 2014).

For sub-experience with sowing time was chosen 550 g.s/sqm because the results of an experience with densities and sowing time made in previous year (figure 1 - yellow) (Trifan, 2014).

At harvesting were made biometric measurements, and determining production $(\mathrm{kg} /$ ha), thousand grain weight (g) and hectolitre mass $(\mathrm{kg} / \mathrm{hl})$ for each experimental variant.
The results were statistically analysed by a method of analysis of variance (ANOVA) and correlation, using Microsoft Excel.

\section{RESULTS AND DISCUSSION}

Average plant height in the sub-experience with different sowing age was higher in chemical fertilization variants (Fig. 2-a). In the subexperience with different densities, ages and fertilization, plant height was between $111 \mathrm{~cm}$ and $122.5 \mathrm{~cm}$ for chemically fertilized and between 99 $\mathrm{cm}$ and $121.2 \mathrm{~cm}$ values to biological fertilized variants. We observed an increase in height plants for biological fertilized variants compared to chemically fertilized variants, only densities of 350 and 450 g.s. /sqm in the second age, and the densities of 250, 350, 450 and 650 g.s. /sqm, in the fourth age. (Fig. 2-b).

In contrast, the average number of ears per plant was higher in fertilized variants of biological ages 4 and 5 in the first sub-experience (Fig. 3a) and in variant of 450 g.s. /sqm density (Fig. 3b).

The medium length of the ear was between 5.2 and $7.5 \mathrm{~cm}$ values in chemically fertilized variants, and between 4.5 and $7 \mathrm{~cm}$ in the variants fertilized biological seeing a significant influence

\begin{tabular}{|c|c|c|c|c|c|c|c|c|c|c|c|c|c|c|}
\hline 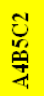 & 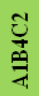 & 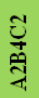 & 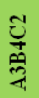 & 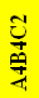 & 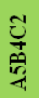 & 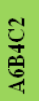 & \begin{tabular}{l}
$\bigcup_{0}$ \\
\multirow{3}{*}{}
\end{tabular} & $\begin{array}{l}\bigcup_{1} \\
\text { ֶ, }\end{array}$ & 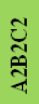 & 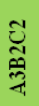 & 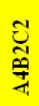 & 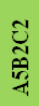 & 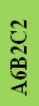 & 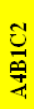 \\
\hline 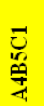 & $\begin{array}{l}\text { 己̈ } \\
\text { 常 }\end{array}$ & 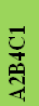 & 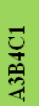 & $\begin{array}{l}\text { 吕 } \\
\text { 孚 }\end{array}$ & 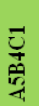 & $\begin{array}{l}\overrightarrow{0} \\
\text { + } \\
\text { : }\end{array}$ & 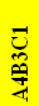 & $\begin{array}{l}\text { 己̈ } \\
\text { 光 }\end{array}$ & $\begin{array}{l}\tilde{\nearrow} \\
\text { 今ै }\end{array}$ & $\begin{array}{l}\text { 己ె } \\
\text { 究 }\end{array}$ & 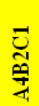 & 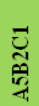 & 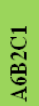 & $\begin{array}{l}\vec{U} \\
\vec{q}\end{array}$ \\
\hline
\end{tabular}

Fig. 1. Map of field experience with different sowing age, densities, chemical and biological fertilization of winter barley

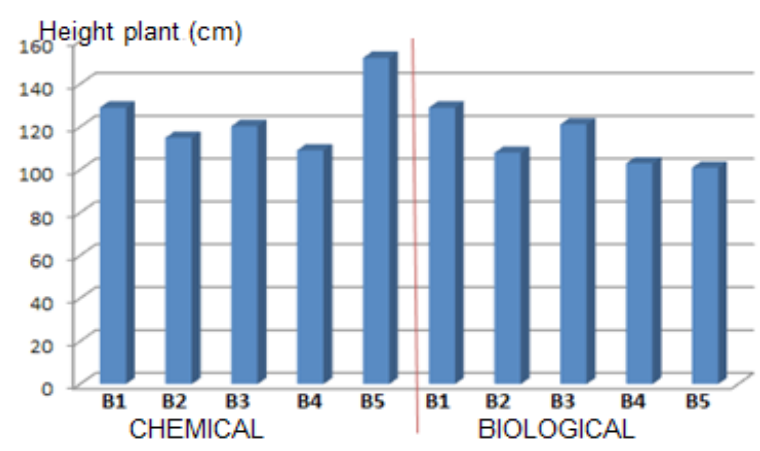

a

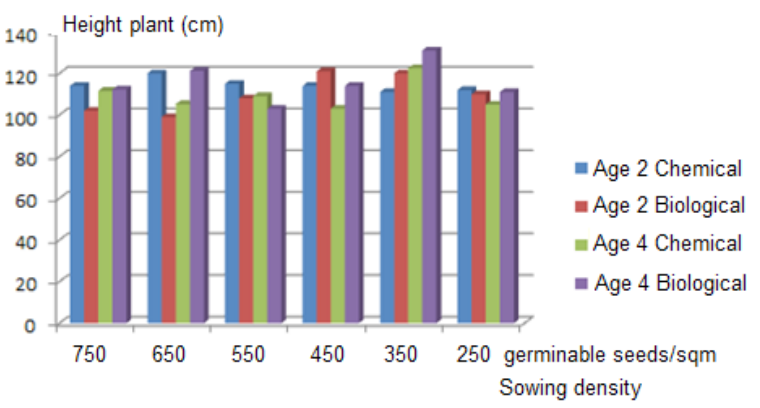

b

Fig. 2. Graphs of height plant in sub-experience with sowing age and different fertilization (a) and in sub-experience with different densities, different sowing ages, chemical and biological fertilization (b) 
of biological fertilization in sub-experience with sowing age and different fertilization (Fig. 4). A significant positive influence was recorded only in variants seeded with a density of 450 and 650 g.s./sqm fertilized biological (Fig. 4b) compared to chemically fertilized variants, otherwise, not biological fertilization increases the length of the ear compared with chemical fertilization.

The average number of kernels/ear was between 39 and 50 values of the variants chemically fertilized and between 33 and 50 for biological fertilized variants in first subexperience (fig. 5a) and number of kernels/ear was significantly positive influenced by biological fertilization in second age for variants sown with 250, 350, 550 and 650 g.s./sqm, while the fourth sowing age variants was all influenced positively by biological fertilization except 350 and 550 g.s./ sqm variants (5b), in the second sub-experience.

In first sub-experience, average weight of ear was increase in chemically fertilized variants than

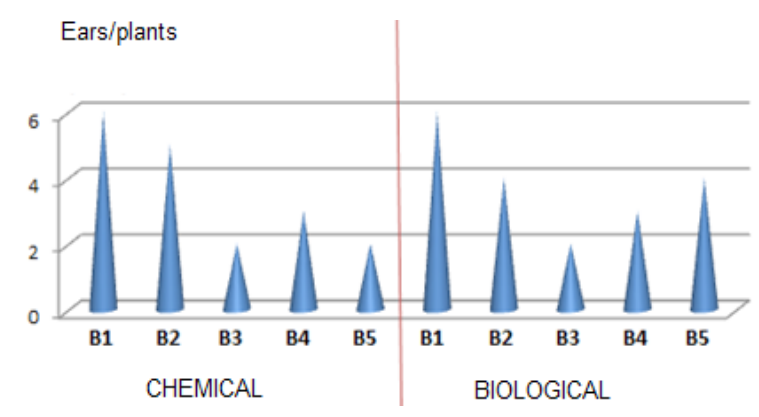

a in biological fertilized variants, except variant sown in the fifth age, which was an increase by $11.7 \%$ compared to chemical fertilized variants (Fig. 6). In the second experience, weight ear was positively influenced by biological fertilization in all variants, except variant with density of 550 g.s/sqm, which represents the optimal period for sowing winter barley, in terms of Baragan North plain (fig. 6 b).

The mass of a thousand grains (TGM) and hectolitre mass (HM) were not significantly influenced by biological fertilization, in the first sub-experience except variant sown in the third age for TGM and sown in the fifth age for HM (fig. 7 ). In the second sub-experience, thousand grain mass (TGM) was positively influenced by biological fertilization compared to variant sown with a density of 250 g.s/sqm, the fourth era (Fig. 7b), where the value increased by $2,4 \%$ for chemically treated variant. In all other experimental variants values of TGM were higher in chemical fertilization

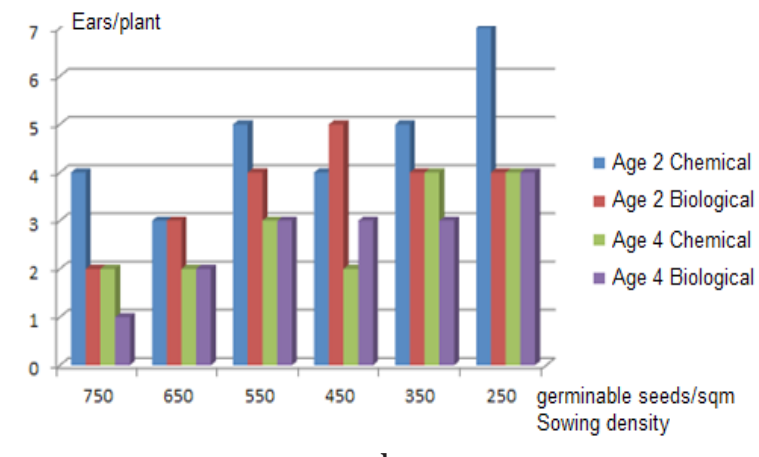

b

Fig. 3. Graphs of average number of ears / plant in winter barley from the experiences with sowing age and different fertilization (a) and from sub-experience with sowing densities, sowing age and different fertilizations (b)

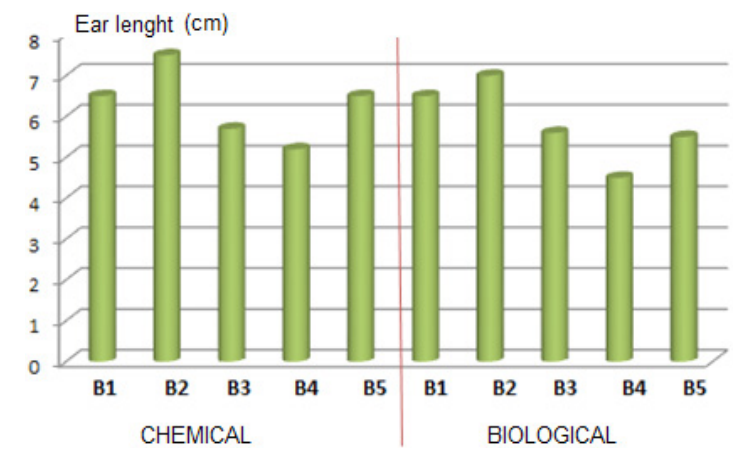

a

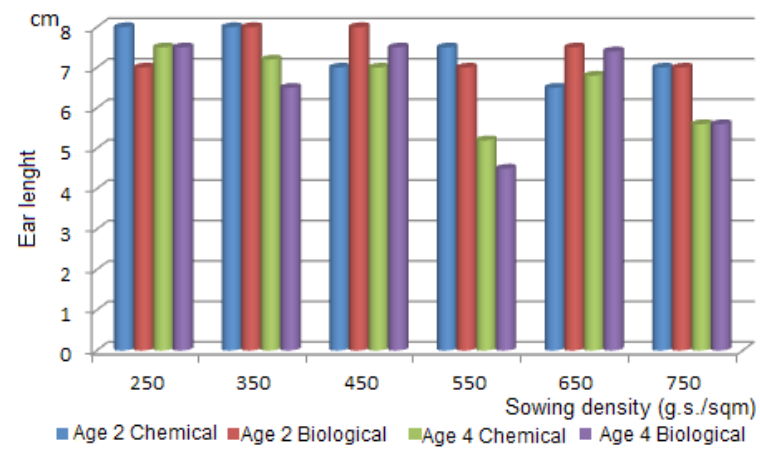

b

Fig. 4. Graphs of ear length of barley plants in sub-experience with sowing age and different fertilization (a), and in sub-experience with densities, sowing age and different fertilization (b) 


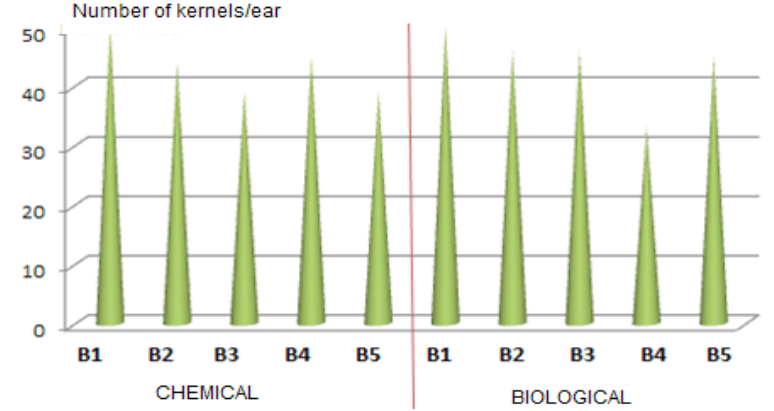

a

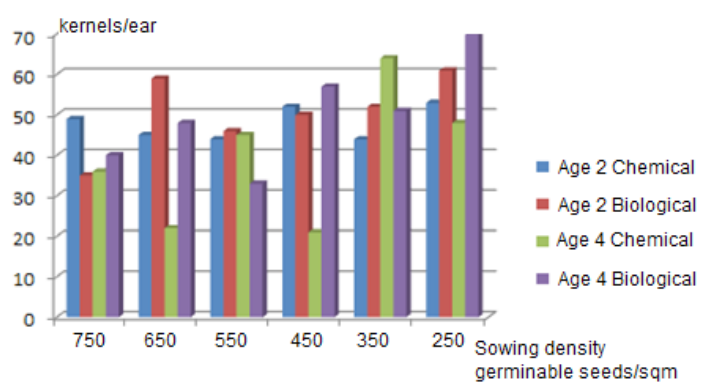

b

Fig. 5. Graphs of average number of kernels/ear for winter barley plants in sub-experience with sowing age and different fertilization (a) and in sub-experience with sowing density, age and different fertilization (b)

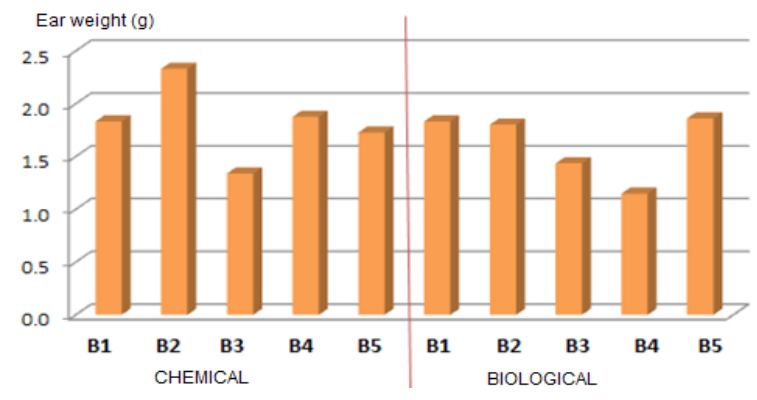

a

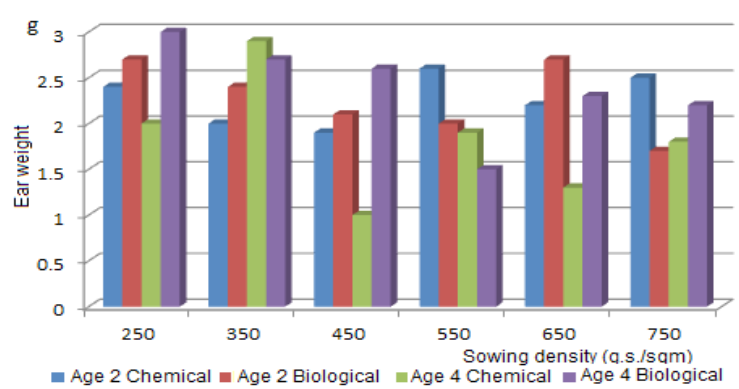

$\mathrm{b}$

Fig. 6. Graphs of average ear weight of winter barley in sub-experience with different sowing age and chemical and biological fertilization (a) and in sub-experience with sowing densities, ages and different fertilization

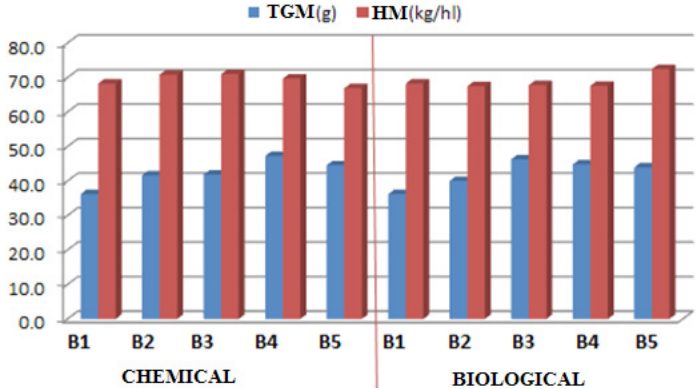

a

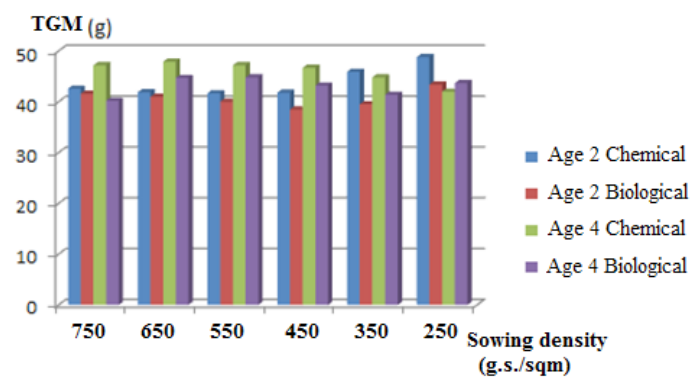

b

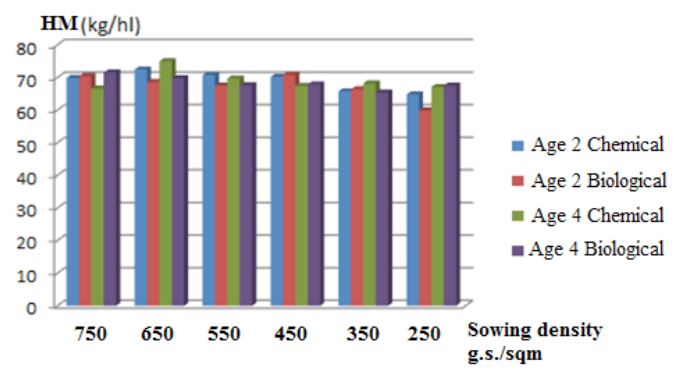

C

Fig. 7. Graphs for mass of a thousand grains and hectolitre mass in winter barley in sub-experience with different ages, chemical and biological fertilization (a) and in sub-experience with different densities, ages and fertilization (b and c) 
compared to biological fertilization. Hectolitre mass (HM) was influenced significantly positive at the variant sown with density of 750 g.s. /sqm in both sowing ages, otherwise influence was insignificant (Fig. 7c).

Average productions per hectare were interpreted statistically by analysis of variance ANOVA test, and control was the average yields obtained in experience. In the first sub-experience, negative yield differences were significant and highly significant distinct in variants ages 1 and 2 , both biologically and chemically fertilized. In the third age, chemically fertilized variant has not obtained significant differences from the control and fertilized variant biologically obtained a very significant positive difference, as well as variants of the fourth age, fertilized both chemically and biologically.

In the fifth age, yield differences were obtained significant distinctive positive in chemically fertilized variants and significant negative in fertilized biologically variant (Tab. 1 and Fig. 8).

In second sub-experience, production recorded positive differences compared to average production of experience for chemically fertilized variants with sowing densities of $250,350,450$, 550 and 750 g.s. /sqm, in the fourth period and the density of 350 g.s. /sqm from the second age. Just biological fertilization recorded positively influence in variants sown densities of 250,350 and 550 g.s. /sqm, in the fourth period. This proves that additional fertilization Algafix when the barley culture have low densities of plants or in sowing late autumn can bring production increases of up to $6 \%$ (Fig. 8b).

Correlations established between the experimental factors (sowing densities, ages and fertilization) and main parameters determined in the experiment are represented in summary chart of Figure 9, and for sub-experience with different

Tab. 1. The analysis of variance for winter barley yields from different sowing ages and chemical and biological fertilization, in crop year 2013 - 2014

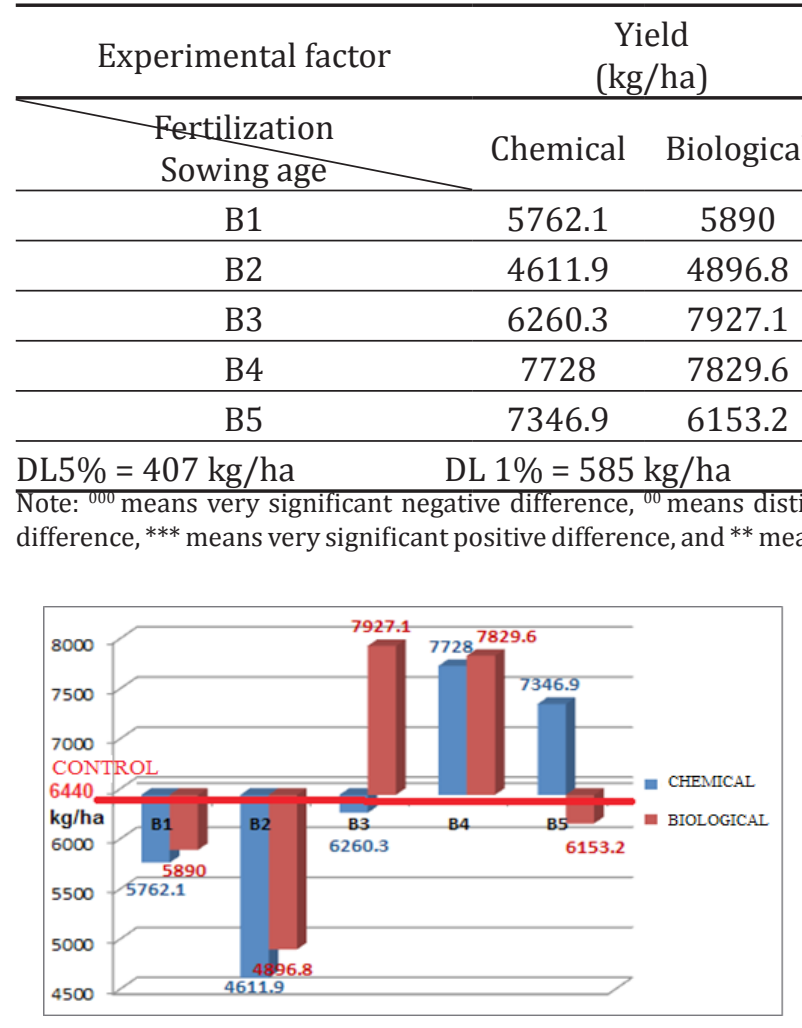

a

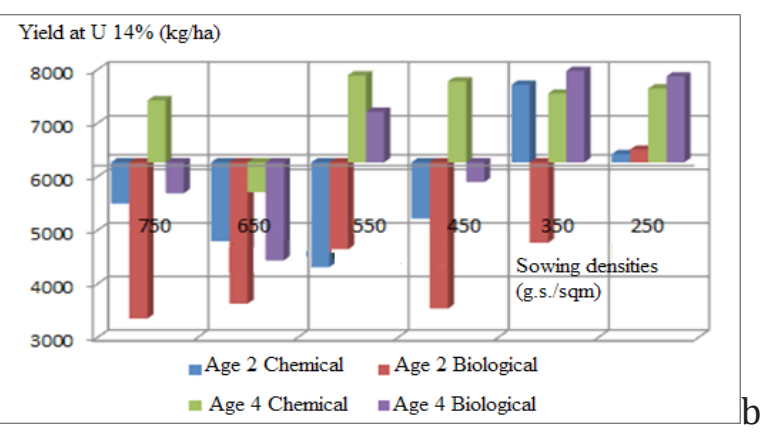

Fig. 8. Yield differences compared to average of experience obtained in sub-experience with different ages and fertilization (a) and in the sub-experience with different sowing densities, ages and fertilization in winter barley (b) 


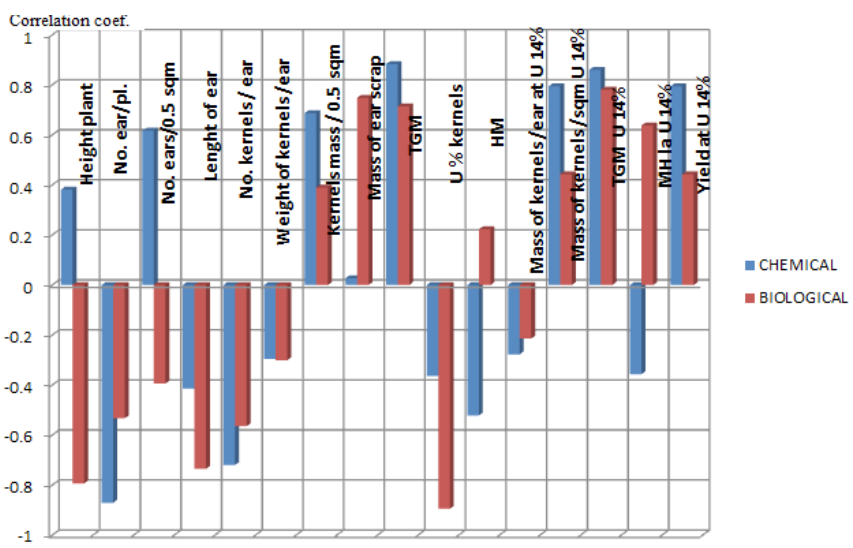

Fig. 9. Graphs of correlations established between sowing densities and parameters determined to winter barley, with chemical and biological fertilization
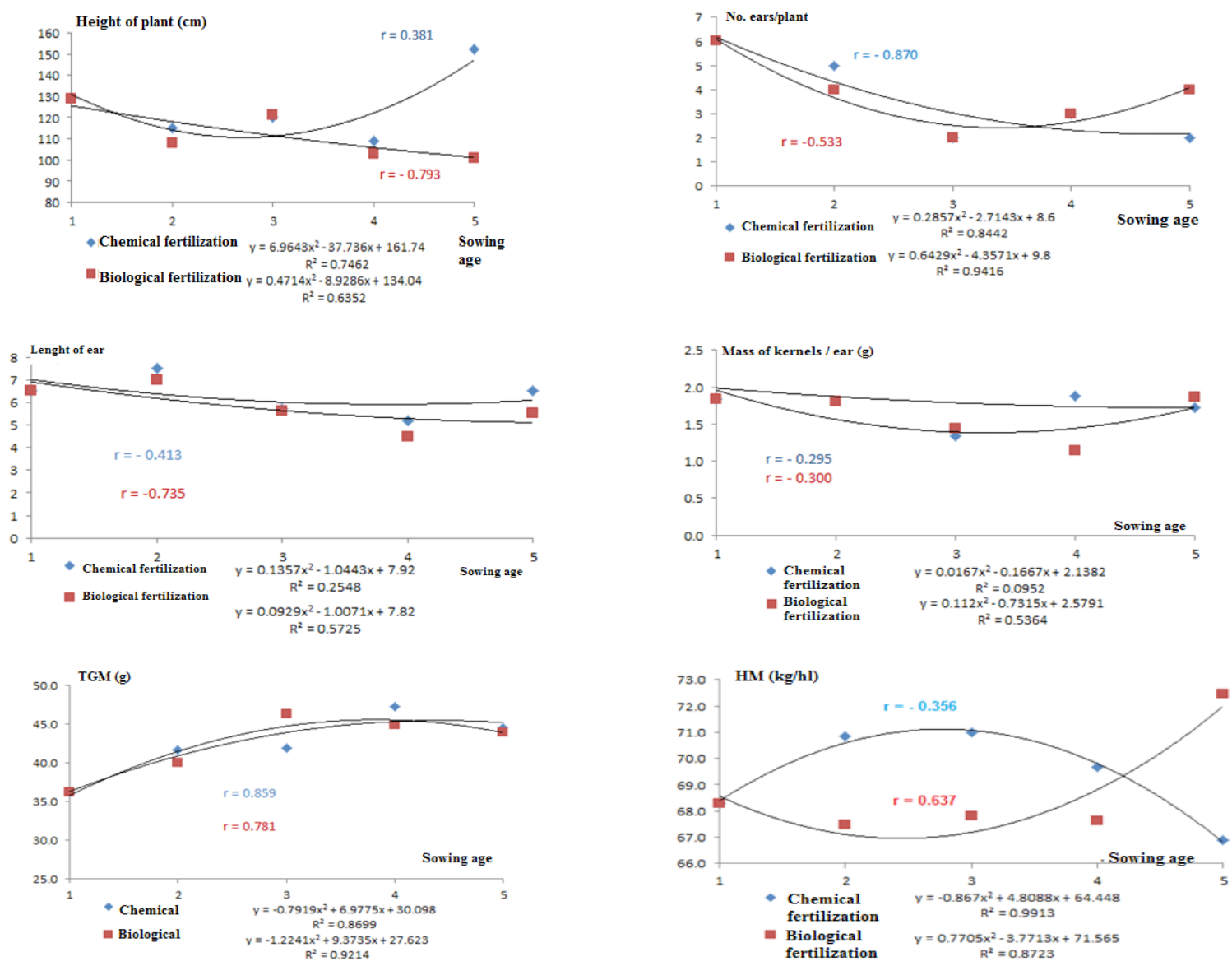

Fig. 10. Graphs of correlations established between the sowing ages and parameters determined to winter barley, in different fertilization

ages the correlation coefficients are specified for each type of fertilizer in the graphs in Figure 10.

We observed a positive correlation between chemical fertilization and height of plants in different sowing densities and ages, in contrast to biological fertilization variants, where was been observed a decrease of height plants. In addition, in hectoliter mass we observed an increase to 
biological fertilized variants, in contrast to chemical fertilized variants (fig. 10).

\section{CONCLUSION}

In the presentresearch work, we demonstrated that winter barley production could be improved by application of organic fertilizer, especially in lower sowing densities and for correction of delayed sowing.

The best production results were obtained from version B3 fertilized biological, meaning an increase of production of $1300 \mathrm{~kg} / \mathrm{ha}$, that is $20 \%$ from the average experience.

There was an increase in productivity elements in biological fertilization at the later ages and densities below ground, which shows that some technical mistakes can be corrected by applying Algafix biofertizer.
Acknowledgements: We wish to thank S.C. AGRO BIOFORCE S.R.L.Company who gave us Algafix biofertilizer to trial in Chiscani experimental center fields, in Agricultural Research and Development Station of Braila.

\section{REFERENCES}

1. Collen B (2006). The barley growth guide.

2. Donald E, Hennessy M, Mullins E, Spink J (2015). Knowledge transfer in Teagasc - Agriculture and Food Development Authority, Ireland http://www.teagasc.ie/ crops/winter/sowing_varieties/

3. Trifan D, Visinescu I, Bularda M (2014). Research about influence of sowing density and sowing time for production level of winter barley in North Baragan Plain conditions, http://agronomyjournal.usamv.ro/ pdf/2014/art67.pdf 